\title{
Tspan18 is a novel regulator of thrombo-inflammation
}

\author{
Rebecca L. Gavin ${ }^{1}$. Chek Ziu Koo ${ }^{1}$ Michael G. Tomlinson ${ }^{1}$ (])
}

Received: 29 January 2020 / Accepted: 6 May 2020 / Published online: 23 May 2020

(c) The Author(s) 2020

\begin{abstract}
The interplay between thrombosis and inflammation, termed thrombo-inflammation, causes acute organ damage in diseases such as ischaemic stroke and venous thrombosis. We have recently identified tetraspanin Tspan18 as a novel regulator of thrombo-inflammation. The tetraspanins are a family of 33 membrane proteins in humans that regulate the trafficking, clustering, and membrane diffusion of specific partner proteins. Tspan 18 partners with the store-operated $\mathrm{Ca}^{2+}$ entry channel Orai1 on endothelial cells. Orai1 appears to be expressed in all cells and is critical in health and disease. Orai1 mutations cause human immunodeficiency, resulting in chronic and often lethal infections, while Orai1-knockout mice die at around the time of birth. Orail is a promising drug target in autoimmune and inflammatory diseases, and Orail inhibitors are in clinical trials. The focus of this review is our work on Tspan18 and Orai1 in Tspan18-knockout mice and Tspan18-knockdown primary human endothelial cells. Orai1 trafficking to the cell surface is partially impaired in the absence of Tspan18, resulting in impaired $\mathrm{Ca}^{2+}$ signaling and impaired release of the thrombo-inflammatory mediator von Willebrand factor following endothelial stimulation. As a consequence, Tspan18-knockout mice are protected in ischemia-reperfusion and deep vein thrombosis models. We provide new evidence that Tspan18 is relatively highly expressed in endothelial cells, through the analysis of publicly available single-cell transcriptomic data. We also present new data, showing that Tspan18 is required for normal $\mathrm{Ca}^{2+}$ signaling in platelets, but the functional consequences are subtle and restricted to mildly defective platelet aggregation and spreading induced by the platelet collagen receptor GPVI. Finally, we generate structural models of human Tspan 18 and Orai 1 and hypothesize that Tspan18 regulates Orai $1 \mathrm{Ca}^{2+}$ channel function at the cell surface by promoting its clustering.
\end{abstract}

Keywords Orai1 $\cdot$ Endothelial cell $\cdot$ Platelet $\cdot$ Store-operated $\mathrm{Ca}^{2+}$ entry $\cdot$ Tetraspanin $\cdot$ Thrombo-inflammation $\cdot$ Tspan18

\section{Introduction}

Thrombo-inflammation is the complex interplay between thrombosis and inflammation that can result in acute organ damage [1-3]. The process is best characterized in mouse models of ischaemic stroke and venous thrombosis. Central to thrombo-inflammation is the release of ultra-large adhesive strings of von Willebrand factor (VWF) from activated endothelial cells, in response to inflammatory mediators

Edited by Charlotte M. de Winde.

This article is part of the Special Issue on Tetraspanins in Infection and Immunity.

Michael G. Tomlinson

m.g.tomlinson@bham.ac.uk

1 School of Biosciences, University of Birmingham, Birmingham, UK such as interleukin-1 (IL-1), IL-6, tumour necrosis factor $\alpha$, thrombin, or histamine [2]. A proportion of the VWF strings remain attached to the endothelial cell surface and recruit platelets and leukocytes. The platelet GPIb-IX-V receptor complex mediates transient rolling of platelets on VWF, which may then firmly adhere if activated to induce adhesion of their $\alpha \operatorname{IIb} \beta 3$ integrins. Leukocytes similarly roll on VWF using their PSGL-1 receptor followed by stable adhesion via $\beta 2$ integrins. Alternatively, leukocytes may be captured indirectly by platelets via interactions with platelet GPIb-IX-V or P-selectin [2]. In addition, monocytes can bind to VWF having first bound platelet-derived GPIb-IXV-positive extracellular vesicles [4]. Together, platelet and leukocyte recruitment lead to further recruitment of inflammatory cells, platelet aggregation, and blockage of vessels causing organ damage [1-3].

VWF is stored by endothelial cells in cigar-shaped vesicles called Weibel-Palade bodies (WPBs). VWF is 
constitutively released at a relatively low level by WPB exocytosis, but can be acutely exocytosed in larger quantities via a mechanism involving $\mathrm{Ca}^{2+}$ signaling following endothelial cell activation [5]. We have recently discovered that tetraspanin Tspan18 is important for endothelial cell $\mathrm{Ca}^{2+}$ signaling, acute VWF release, and thrombo-inflammation, by interacting with the store-operated $\mathrm{Ca}^{2+}$ entry channel Orai1 and promoting its trafficking to the cell surface [6]. This review will describe our current knowledge of Tspan 18 expression and function, and will speculate on the molecular mechanism by which Tspan 18 regulates Orai1.

\section{The store-operated $\mathrm{Ca}^{2+}$ entry channel Orai 1}

Orai1 was identified as the long-sought-after store-operated $\mathrm{Ca}^{2+}$ entry channel through three publications in 2006 [7-9]. $\mathrm{Ca}^{2+}$ influx through Orai1 channels on the cell surface is termed store-operated $\mathrm{Ca}^{2+}$ entry, because it is induced by emptying of $\mathrm{Ca}^{2+}$ stores in the endoplasmic reticulum (ER). Orai1 has four transmembrane regions and intracellular $N$ - and $C$-termini (Fig. 1) [10]. Structural studies suggest that Orail functions as a hexamer, forming a channel that mediates a characteristic $\mathrm{Ca}^{2+}$ release-activated $\mathrm{Ca}^{2+}$ current, termed $\mathrm{I}_{\mathrm{CRAC}}$. The $\mathrm{I}_{\mathrm{CRAC}}$ is distinguished by high $\mathrm{Ca}^{2+}$ selectivity, a very low unitary conductance, with an inwardly-rectifying current-to-voltage ratio and a very positive reverse potential. The other Orai family members, Orai2 and Orai3, are approximately $60 \%$ identical to Orail by protein sequence. They are less well studied, but may form their own $\mathrm{Ca}^{2+}$ channels or combine with Orai1 to form heteromeric channels [10].
Orai1 appears to be expressed in all cells and is critical in health and disease processes. Indeed, Orai1-knockout mice die at around the time of birth, and Orai 1 mutations in humans cause immunodeficiency, leading to chronic infections that are often lethal, and various non-immunological symptoms [11]. As previously mentioned, Orai1 channel opening is induced by emptying of $\mathrm{ER} \mathrm{Ca}^{2+}$ stores [10]. Such emptying is the downstream consequence of signaling by cell surface receptors, including $\mathrm{G}$ protein-coupled receptors (GPCRs), receptor tyrosine kinases, and immunoreceptors such as B- and T-cell antigen receptors. Their stimulation activates phospholipase $\mathrm{C}$, generating the second messenger $\mathrm{IP}_{3}$, which induces $\mathrm{Ca}^{2+}$ release from $\mathrm{IP}_{3}$ receptor $\mathrm{Ca}^{2+}$ channels on the ER. The release of $\mathrm{Ca}^{2+}$ is sensed by ER-localized STIM1 and STIM2 proteins, which undergo conformational change to engage with and activate Orail channels on the cell surface in characteristic clusters, or puncta. The influx of $\mathrm{Ca}^{2+}$ replenishes ER stores and, importantly, activates a variety of $\mathrm{Ca}^{2+}$-responsive signaling proteins to dictate cell function, such as changes in gene expression through activation of NFAT transcription factors [10].

The immunodeficiency observed in the absence of Orai1 has made this protein a promising drug target to treat diseases caused by an over-active immune system, such as autoimmune and inflammatory diseases [12, 13]. Indeed, five inhibitors of store-operated $\mathrm{Ca}^{2+}$ entry have recently entered clinical trials for diseases such as acute pancreatitis, asthma, non-Hodgkin's lymphoma, and the skin disease plaque psoriasis $[12,13]$. However, based on the phenotypes of Orai1-deficient humans and mice, there are concerns that inhibition of Orail on every cell in the body could lead to toxic side effects, particularly chronic immunosuppression

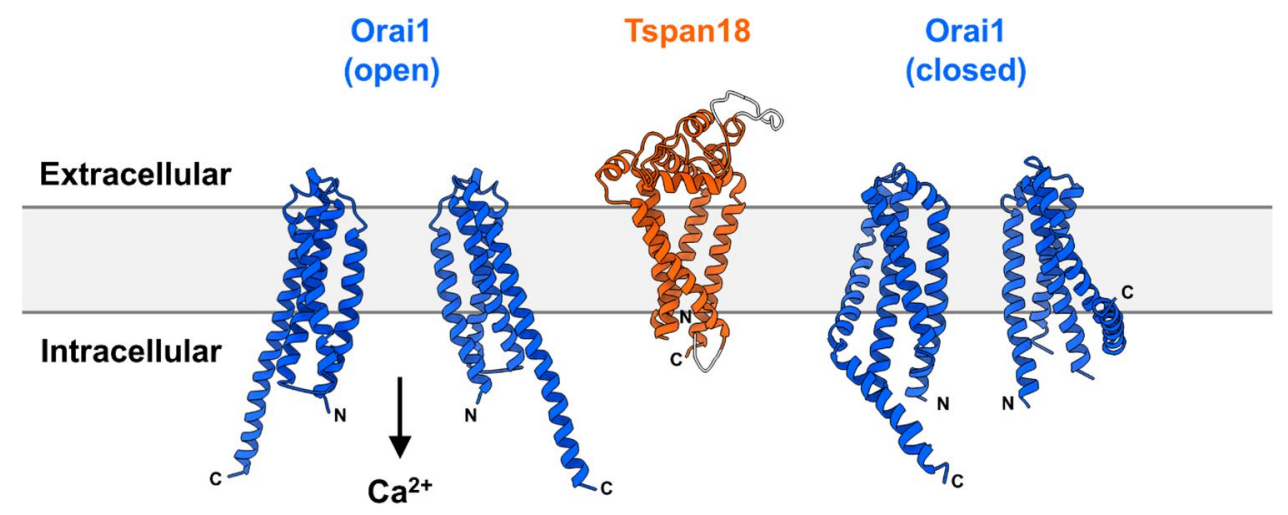

Fig. 1 Predicted structures of human Tspan18 and Orai1. Model structures of human Tspan18 (UniProt accession number Q96SJ8) and human Orai1 (UniProt accession number Q96D31) were generated with Phyre2 [62]. Human Tspan18 was modelled based on the crystal structure of human CD81 (PDB: 5TCX) [33]. Of the total protein length, $92 \%$ was predicted with $100 \%$ confidence (orange region) and the rest was generated ab initio (grey region). The crystal structures of Drosophila Orail subunits in open (PDB: 6BBF) [63] and closed (PDB: 4HKR) [64] conformations were used as templates for human Orai1 and yielded $100 \%$ confidence for $50 \%$ and $58 \%$ of the total protein length, respectively. The core Orail structures are shown; low confidence loop regions on the extracellular and intracellular parts of Orai1 were omitted. Orai1 exists as a hexamer, but only two subunits are depicted for clarity 
and reduced muscle strength and endurance [13]. Hence, there is a need to more fully understand the mechanisms of tissue-specific Orai1 regulation, to explore whether novel, more selective inhibitory strategies might inhibit its function in disease without severe general toxicity.

\section{Tetraspanins regulate the trafficking and clustering of their partner proteins}

The tetraspanins are a superfamily of membrane proteins with four transmembrane regions that interact with specific partner proteins, and regulate their trafficking to the cell surface and subsequent lateral mobility and clustering [14, 15]. Tetraspanins appear to exist in all multicellular organisms, from plants to fungi to mammals, and there are 33 tetraspanins in humans [16]. Examples of tetraspanin/partner protein complexes are tetraspanin CD151 and lamininbinding integrins such as $\alpha 3 \beta 1$ and $\alpha 6 \beta 1$ [17], tetraspanin CD81 and the B-cell receptor co-receptor CD19 [18], and Tspan12 and the Wnt/Norrin receptor Frizzled-4 [19]. The clustering of the partner appears to be the prominent role of CD151 and Tspan12 in these examples, whereas trafficking to the cell surface is the major impact of CD81 on CD19. In each case, tetraspanin deletion or mutation in humans and mice leads to phenotypes that resemble the deletion of the partner [17-19], thus providing genetic evidence for the importance of the interaction. In addition, we and others have shown that a subgroup of six tetraspanins, comprising Tspan5, 10, 14, 15, 17, and 33, and collectively known as the TspanC8s, interact with and regulate trafficking from the endoplasmic reticulum of the 'molecular scissor' a disintegrin and metalloprotease 10 (ADAM10) [20-23]. ADAM10 cleaves the extracellular regions from target proteins in a process termed ectodomain shedding. ADAM10 substrates number over 100 and include Notch cell fate regulators, amyloid precursor protein, cadherin adhesion molecules, growth factors, and chemokines. We have proposed a 'six scissor' hypothesis, which postulates that ADAM10 is not one scissor, but six different scissors with different substrates depending on which of the six regulatory TspanC8s it is associated with [20-22]. Substantial recent evidence supports this hypothesis [24-32].

Finally, tetraspanins have recently emerged as potential drug targets, following the discovery of the remarkable structure of CD81, the first tetraspanin structure to be solved by X-ray crystallography [33]. CD81 is cone-shaped with a cholesterol-binding cavity and is proposed to undergo a dramatic conformational change if cholesterol is removed [33]. This suggests that tetraspanins might function as 'molecular switches' to regulate their partners, but this has yet to be proved. If true, it may be possible to inhibit tetraspanin function using antibodies that lock the tetraspanin in a particular conformation. Alternatively, antibodies could inhibit by down-regulating tetraspanins or disrupting interactions with partners.

\section{Tspan 18 regulates Orai1/ $\mathrm{Ca}^{2+}$ signaling on endothelial cells}

We recently reported that Orai 1 is regulated by Tspan18, a previously uncharacterized tetraspanin in mammalian cells [6]. Our work was initiated by a functional screen for effects of tetraspanins on $\mathrm{Ca}^{2+}$ signaling, which found that overexpression of Tspan18, but not other tetraspanins, activates the $\mathrm{Ca}^{2+}$-responsive NFAT transcription factor by 20 -fold in an Orai1-dependent manner [6]. Furthermore, Tspan 18 co-immunoprecipitates with Orai1, but other tetraspanins do not. In the current absence of an effective Tspan18 antibody, we used RT-PCR to demonstrate Tspan 18 expression in human endothelial cells, but not most other cell types. This was supported by our analyses of publicly available RNA-Seq data from mouse lung and brain, which showed that Tspan18 is most highly expressed in endothelial cells of these organs [6]. Analysis of single-cell RNA-Seq data from 20 mouse organs provides further support, since 9 of the 14 most highly Tspan18-expressing cell types are endothelial cells (Fig. 2) [34]. Tspan18 is not entirely restricted to endothelial cells, since there is notable expression in bladder cells and weaker expression in certain other cell types (Fig. 2).

We further showed that Tspan 18 knockdown in primary human umbilical vein endothelial cells (HUVECs) impairs $\mathrm{Ca}^{2+}$ signaling by 55-70\% following stimulation with the GPCR agonists histamine or thrombin, similar to Orai1 knockdown [6]. Orai1 surface localisation is $70 \%$ reduced following Tspan 18 knockdown, suggesting a role for Tspan 18 in trafficking Orai1 from the ER. Tspan18knockout mice are grossly normal and breed as both homozygote knockouts and heterozygotes, the latter yielding offspring at Mendelian ratios. However, the Tspan18knockout mice display endothelial defects that yield partial protection in two thrombo-inflammatory models: a deep vein thrombosis model (60\% reduction in thrombus size) and an ischemia-reperfusion injury heart attack model (50\% reduced platelet deposition). Furthermore, there is a $90 \%$ and 50\% reduction in agonist-induced release of VWF from endothelial cells in vitro and in vivo models, respectively [6]. Together, our data strongly suggest that Tspan18 interacts with Orai1 and regulates its trafficking to the endothelial cell surface, a process which is critical for normal endothelial cell $\mathrm{Ca}^{2+}$ signaling and consequent thrombo-inflammatory responses.

In addition to their thrombo-inflammatory phenotypes, Tspan18-knockout mice have a haemostasis defect, as 
Fig. 2 Tspan 18 is preferentially expressed by endothelial cells. Mouse Tspan18 expression was analysed from publicly available single-cell RNA-Seq data sets from the Tabula Muris Consortium [34], which contains data from 53,760 cells from 20 organs or tissues of seven mice. Tabula Muris data for gene counts from cells sorted by flow cytometry were normalized to counts per million (cpm) and presented as $\ln (1+\mathrm{cpm})$. Data from the top 20 cell types (tissue of origin in brackets), ranked by mean expression, were visualized as violin plots; $\mathrm{n}$ represents number of cells

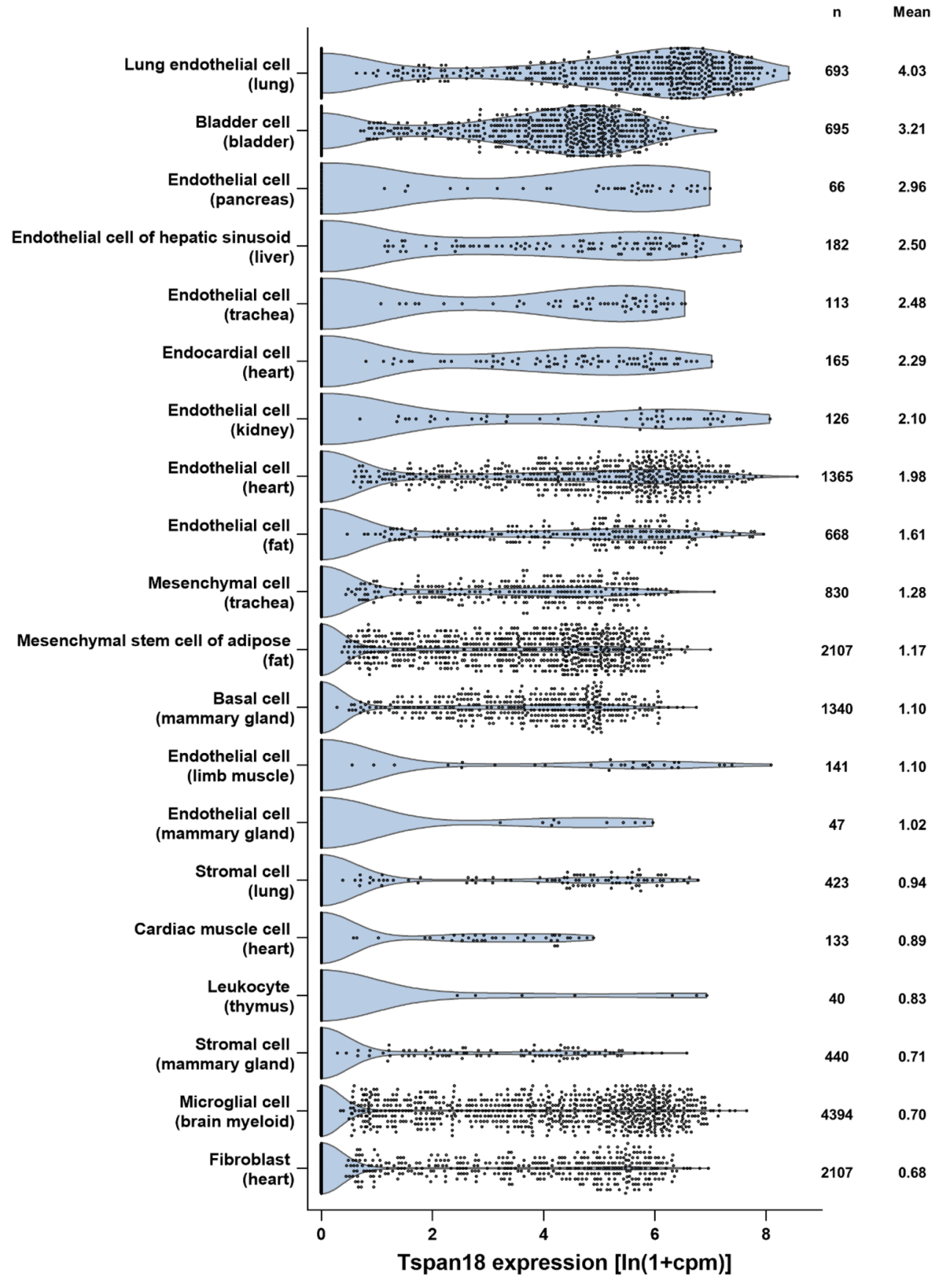

channels, followed by VWF release and platelet recruitment, such that cessation of bleeding would be quicker than in the absence of such VWF release. The haemostasis defect in endothelial-specific VWF-knockout mice [35, 36] would appear to support this hypothesis. However, interpretation of these data is complicated by the strikingly reduced VWF concentration in the plasma of these mice, which is thought to be responsible for increased bleeding $[35,36]$. Plasma VWF concentration is normal in Tspan18-knockout mice [6], and thus, we believe that Tspan $18 / \mathrm{Orai} 1 / \mathrm{Ca}^{2+}$ signaling is important for acute VWF 
release following cell activation, in contrast to the relatively low-level release of VWF that is known to occur constitutively [5]. We propose that acute VWF release has a role in promoting haemostasis, but this will be challenging to test experimentally.

A recent study identifies the Tspan 18 orthologue tspan $18 \mathrm{~b}$ as an endothelial-expressed gene in zebrafish, which is required for normal blood vessel development, but its mechanism of action was not investigated [37]. Since VWF is known to promote blood vessel development [38], we propose that impaired Orai $1 / \mathrm{Ca}^{2+}$ signaling and impaired VWF release may be responsible for the phenotype in tspan $18 b$-knockdown zebrafish. Thus, the role of Tspan 18 in regulating Orai1/ $\mathrm{Ca}^{2+}$ signaling in endothelial cells may be conserved across diverse vertebrate species. It remains to be determined whether blood vessel development may also be impaired in Tspan18-knockout mice, although the grossly normal vasculature in adult kidney, pancreas, and ear [6] suggests that any developmental defect may only be subtle or delayed.

An emerging idea in the Orail field is that the extent of clustering (promoted by STIM proteins) affects the nature of the ensuing $\mathrm{Ca}^{2+}$ signal and downstream cellular responses $[39,40]$. We hypothesize that Tspan 18 provides an additional mechanism of Orail clustering in endothelial cells, and that Tspan18/Orai 1 complexes may create a $\mathrm{Ca}^{2+}$ channel with membrane dynamics and electrophysiological properties that are distinct from Orai1 alone. A predicted structural model of Tspan 18, based on the crystal structure of CD81 [33], is shown alongside the crystal structures of the Orail channel in closed and open conformations, to show the comparative dimensions of the proteins (Fig. 1); it has yet to be determined if Tspan18 interacts with higher affinity to the closed or open forms. Mechanistically, Tspan 18 may pre-cluster Orai 1 channels, resulting in stronger, more rapid $\mathrm{Ca}^{2+}$ signaling in response to agonists, which may be critical for endothelial cell function in blood vessel growth and in thrombo-inflammation. Furthermore, the proposed function of tetraspanins as molecular switches [33] might enable Tspan 18 to modulate Orai1 via conformational change. We believe that Tspan18 is a potential drug target for the treatment of endothelial-driven inflammatory diseases, cancer angiogenesis, and retinal neovascularisation, which is the most common form of vision loss in the western world. Importantly, targeting Tspan 18 may enable Orai 1 inhibition in a relatively endothelial-specific manner, so avoiding the likely toxicity that would result from inhibiting this important $\mathrm{Ca}^{2+}$ channel on all cells in the body. Targeting tetraspanins is not without precedent, since an antibody to tetraspanin CD37 is in clinical trials for chronic lymphocytic leukaemia [41].

\section{A subtle role for Tspan 18 in platelet $\mathrm{Ca}^{2+}$ signaling and aggregation}

In addition to the cell types included in Fig. 2, Tspan18 has been detected in human platelets by proteomics [42, 43], and in human and mouse platelets and megakaryocytes at the mRNA level [44-46]. Platelets have a pivotal role in haemostasis, but the bleeding phenotype in the Tspan18knockout mice is not due to platelet dysfunction, because the experiments with fetal liver chimeras showed that this is a result of Tspan 18 deletion in non-haematopoietic cells [6]. Furthermore, Tspan18-knockout platelets aggregate normally in response to the platelet agonists collagen or thrombin [6].

To investigate whether Tspan 18 has some role in platelet $\mathrm{Ca}^{2+}$ signaling, platelets were loaded with the $\mathrm{Ca}^{2+}$-sensitive dye Fura-2-AM. Platelets were stimulated with collagen-related peptide, a specific agonist for the collagen receptor GPVI which activates platelets via nonreceptor tyrosine kinase signaling. Intracellular $\mathrm{Ca}^{2+}$ concentrations were then monitored with a fluorimeter. The rate of cellular $\mathrm{Ca}^{2+}$ accumulation and the maximal $\mathrm{Ca}^{2+}$ concentration after $10 \mathrm{~min}$ were significantly reduced in Tspan18-knockout platelets (Fig. 3a). A similar result was obtained following stimulation with collagen (Fig. 3b). No significant effect was observed following stimulation with thrombin, which activates platelets via a GPCR (Fig. 3c). To assess store-operated $\mathrm{Ca}^{2+}$ entry, platelets were treated in the absence of extracellular $\mathrm{Ca}^{2+}$ with thapsigargin, which inhibits sarco/endoplasmic reticulum $\mathrm{Ca}^{2+}$-ATPase channels to cause $\mathrm{Ca}^{2+}$ store emptying. A reduction in the rate of release and maximal $\mathrm{Ca}^{2+}$ increase was observed in Tspan18-knockout platelets (Fig. 3d). Subsequent addition of extracellular $\mathrm{Ca}^{2+}$ to the platelets, allowing storeoperated $\mathrm{Ca}^{2+}$ entry to occur, revealed impaired $\mathrm{Ca}^{2+}$ entry in the absence of Tspan18 (Fig. 3e).

To further explore a potential functional role for Tspan 18 in platelets, in vitro aggregation assays were employed. Defective aggregation of Tspan18-knockout platelets was observed in response to the collagen-related peptide at the intermediate concentration (Fig. 4a), which was partially rescued at high concentration (Fig. 4b). However, aggregation induced by the physiological agonist for GPVI, collagen, which also binds $\alpha 2 \beta 1$ integrin, was normal for Tspan18-knockout platelets (Fig. 4c, d), as we previously reported [6]. Aggregation was also normal when induced by threshold levels of other platelet agonists, such as anti-CLEC-2 antibody, thrombin, or ADP (Fig. 4e-h). To determine whether this GPVI-specific aggregation defect extends to platelet spreading, platelets were plated on glass coverslips coated with collagenrelated peptide or fibrinogen; the latter binds to $\alpha \operatorname{IIb} \beta 3$, the 
Fig. 3 GPVI-induced $\mathrm{Ca}^{2+}$ signaling and store-operated $\mathrm{Ca}^{2+}$ entry is reduced in Tspan18-knockout platelets. Washed platelets from Tspan $18^{+/+}$and Tspan $18^{-/-}$mice were loaded with the $\mathrm{Ca}^{2+}$ sensitive dye Fura-2 AM and $\mathrm{Ca}^{2+}$ measurements taken using a luminescence spectrophotometer. Collated data were fitted to an exponential one-phase association equation, shown in the left-hand panels, and maximal $\mathrm{Ca}^{2+}$ concentration was calculated, shown in the right-hand column. Platelets were stimulated with a $1 \mu \mathrm{g} / \mathrm{ml}$ collagen-related peptide (CRP), b $3 \mu \mathrm{g} / \mathrm{ml}$ collagen, and c 0.06 units $/ \mathrm{ml}$ thrombin. d Platelets were treated in the absence of extracellular $\mathrm{Ca}^{2+}$ with thapsigargin (TG) to induce emptying of the intracellular $\mathrm{Ca}^{2+}$ stores. e The experiment in panel (d) was extended by the addition of $1.5 \mathrm{mM} \mathrm{Ca}^{2+}$ to the extracellular buffer. The rate constants were compared using an $f$ test $(* * *$ denotes $P<0.001)$. Maximal $\mathrm{Ca}^{2+}$ concentrations were analysed by $t$ test (* denotes $P<0.05$; ns denotes not significant). Error bars represent the standard error of the mean from 2-6 independent experiments. Detailed methods are available online (https:// etheses.bham.ac.uk/id/eprint/5903/)

major platelet integrin. Tspan18-knockout platelet spreading was impaired on collagen-related peptide but normal on fibrinogen (Fig. 5a). When aggregate formation on collagen was assessed in whole blood using a flow-adhesion system, no defect in dynamics or total coverage area of platelet aggregates was observed for Tspan18-knockout platelets (Fig. 5b). Together, these data suggest a relatively mild but specific defect in GPVI-induced activation in the absence of Tspan18, which can be overcome at high doses of collagen-related peptide or by collagen, the latter which engages both GPVI and $\alpha 2 \beta 1$ integrin; it is possible that signaling induced by the collagen-binding integrin $\alpha 2 \beta 1$ $[47,48]$ is sufficient to overcome the mild GPVI-specific aggregation defect.

GPVI signals via an immunoreceptor tyrosine-based activation motif (ITAM) within its associated FcR $\gamma$ chain, to activate non-receptor tyrosine kinases of the Src, Syk, and Btk families and downstream phospholipase C (PLC) $\gamma 2$ and $\mathrm{Ca}^{2+}$ signaling. The idea that GPVI signaling is impaired in Tspan18-knockout platelets because of impaired Orai1 function is supported by normal upstream signaling, namely tyrosine phosphorylation in response to collagen-related peptide (Fig. 6). Interestingly, in Orai1-knockout platelets, store-operated $\mathrm{Ca}^{2+}$ entry is reduced by $80-90 \%$, but the aggregation defect is specific to GPVI [49]. It remains unclear why GPVI-induced platelet aggregation is so reliant on Orai1, but the similarities in phenotype between Orai1 and Tspan18 deficiencies are consistent with the idea that Orai1 is Tspan18-regulated.
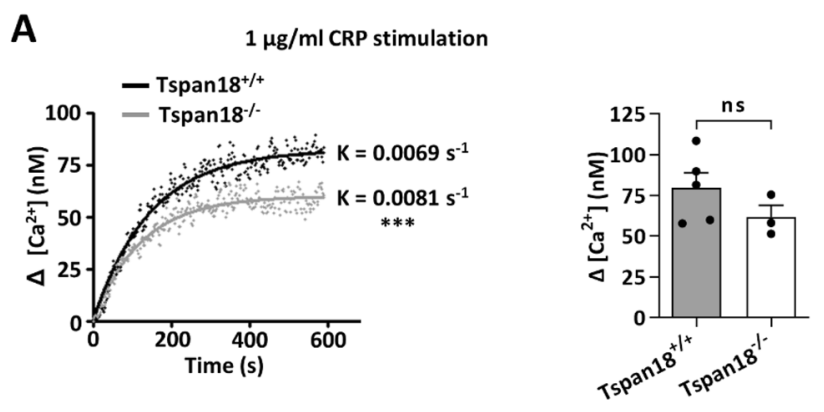

B

$3 \mu \mathrm{g} / \mathrm{ml}$ Collagen stimulation
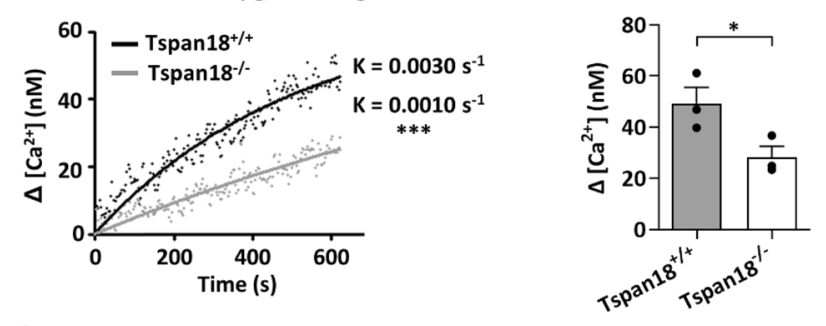

C

$0.06 \mathrm{U} / \mathrm{ml}$ Thrombin stimulation
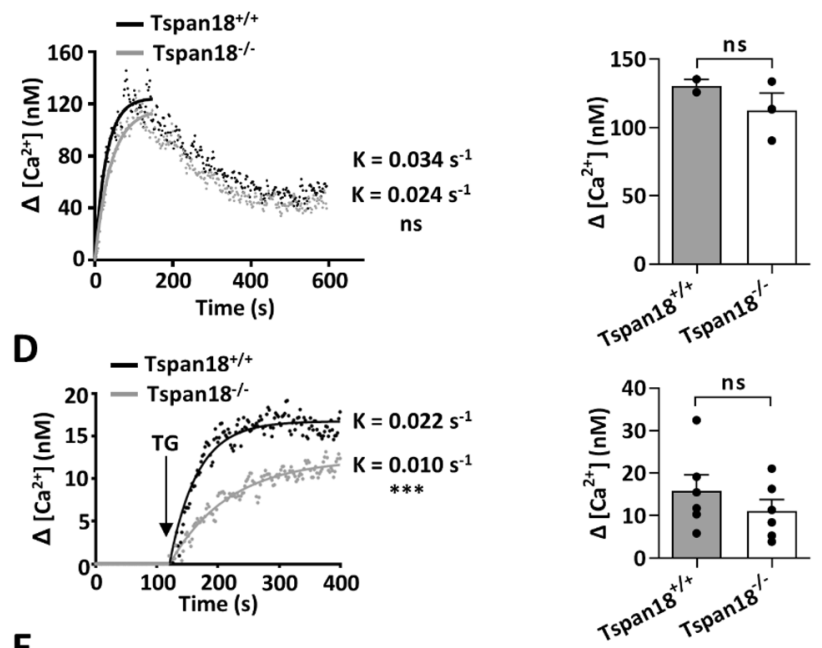

E
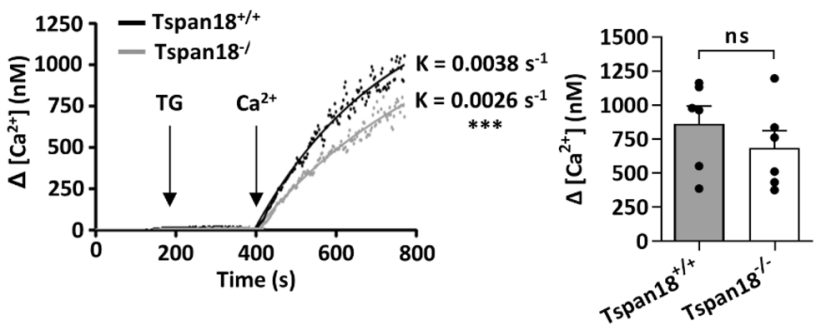

Additional roles for Tspan 18: chick
embryonic development and links
to schizophrenia

Before our recent characterization of Tspan 18, the only functional studies on Tspan 18 were in chick embryos, in which Tspan 18 is required for neural crest cell migration, albeit without a major effect on embryonic development [50, 51]. Neural crest cells are a population of cells that arise 

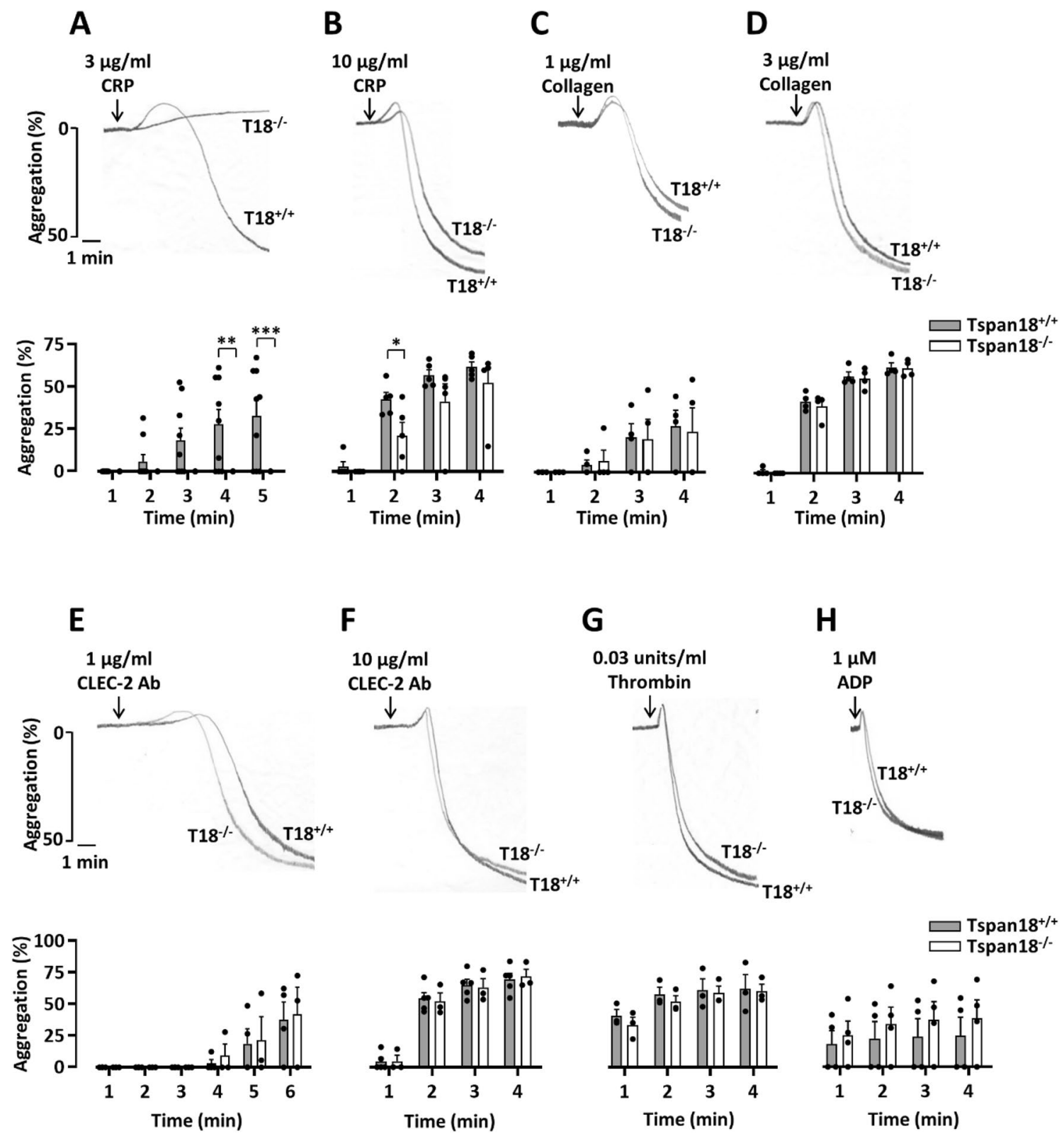

Fig. 4 Tspan18-deficient platelets have a specific aggregation defect downstream of GPVI. Mouse platelets were isolated from whole blood taken from Tspan $18^{+/+}$and Tspan $18^{-/-}$mice. Washed platelets were activated with a $3 \mu \mathrm{g} / \mathrm{ml}$ or b $10 \mu \mathrm{g} / \mathrm{ml}$ of the GPVI-specific agonist collagen-related peptide (CRP), c $1 \mu \mathrm{g} / \mathrm{ml}$ or d $3 \mu \mathrm{g} / \mathrm{ml}$ collagen, e $1 \mu \mathrm{g} / \mathrm{ml}$ or f $10 \mu \mathrm{g} / \mathrm{ml}$ CLEC-2 antibody, or $\mathbf{g} 0.03$ units $/ \mathrm{ml}$ thrombin. h Platelets in PRP were activated with $1 \mu \mathrm{M}$ ADP. Aggre-

transiently during vertebrate development from the ectoderm germ layer. They undergo epithelial-to-mesenchymal transition to migrate and differentiate into a diverse range of cell types. Tspan 18 mRNA is expressed in pre-migratory neural crest cells, but is down-regulated when the cells migrate, and forced Tspan18 over-expression prevents migration [51]. There is no evidence that Tspan 18 is regulating Orai1/ $\mathrm{Ca}^{2+}$ signaling in this process. Instead, Tspan 18 expression gation was measured via light transmission with stirring. Representative traces are shown in the upper panels and quantitated \% aggregation per minute shown in the lower panels. A two-way ANOVA was performed on arcsine-transformed data $(*$ denotes $P<0.05$, ** denotes $P<0.01$ and $* * *$ denotes $P<0.001$ ). Error bars represent the standard error of the mean from 3-9 pairs of mice. Detailed methods are available online (https://etheses.bham.ac.uk/id/eprint/5903/)

stabilizes the expression of the cell-cell adhesion molecule cadherin 6 at the protein level; down-regulation of cadherin 6-mediated cell-cell interactions is important to allow the cells to disengage from each other and migrate [51]. It has yet to be investigated if Tspan 18 regulates cadherin 6 in mammalian cells. Cadherin 6 does not appear to be expressed in endothelial cells in mice [34]. Indeed, cadherin 6 is not expressed by most normal cell types, and is best 

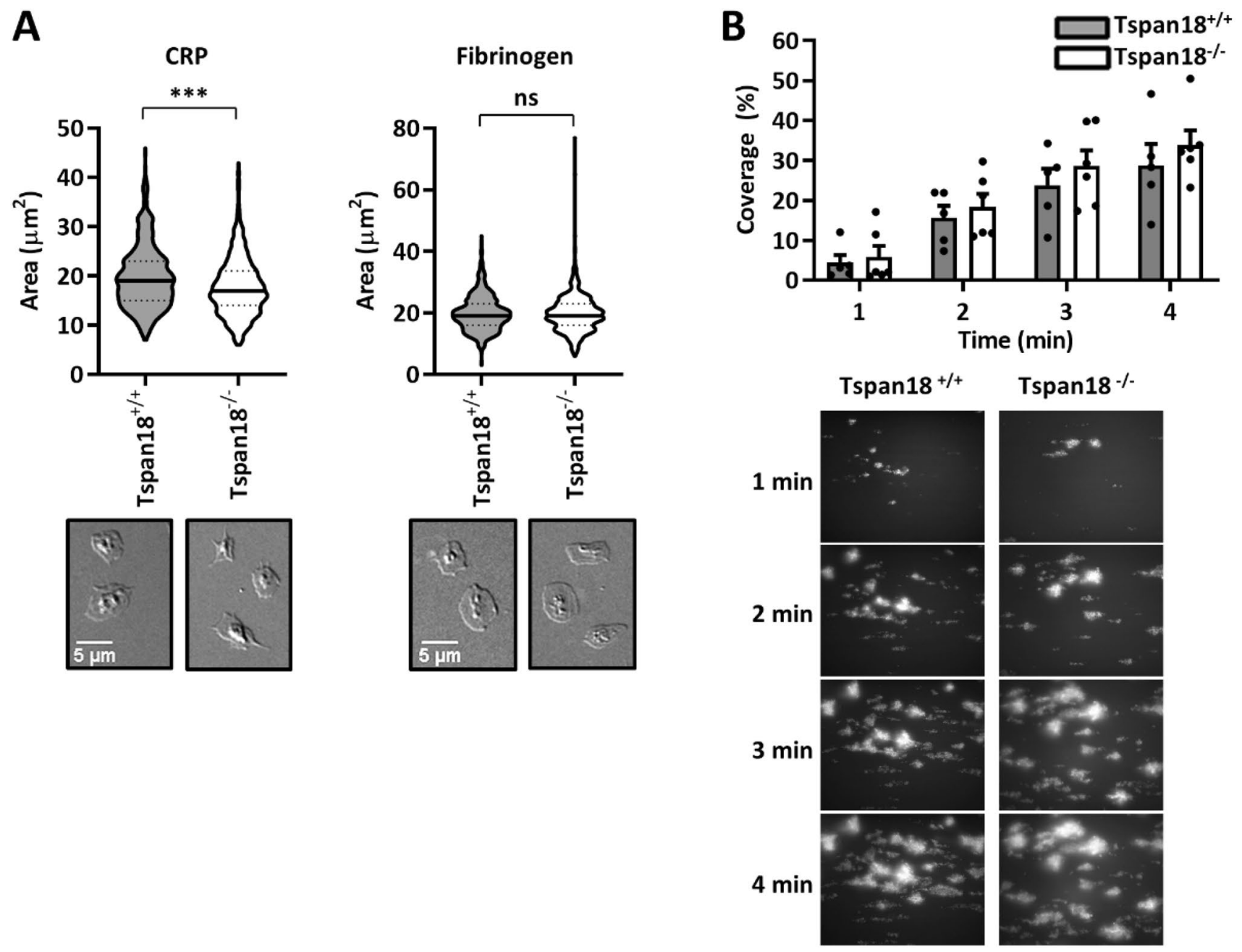

Fig. 5 Tspan18-deficient platelets have a specific spreading defect downstream of GPVI, but aggregate formation under flow is normal. a Washed platelets from Tspan $18^{+/+}$and Tspan $18^{-/-}$mice were exposed to coverslips coated with $10 \mu \mathrm{g} / \mathrm{ml}$ collagen-related peptide (CRP) or $100 \mu \mathrm{g} / \mathrm{ml}$ fibrinogen. The area of the adhered platelets was measured and quantitated. Upper panels show quantitation in the form of violin plots from 4 pairs of mice ( 150 platelets were analysed per mouse). All data were analysed by $t$ test (*** denotes $P<0.001$, ns denotes not significant). Lower panels are representative DIC microscopy images. b Whole blood from Tspan $18^{+/+}$and Tspan $18^{-/-}$

studied for its expression on renal, ovarian, and thyroid cancers [52]. One cell type in which Tspan 18 and cadherin 6 are co-expressed is the platelet. Cadherin 6 blocking strategies suggested a subtle role for cadherin 6 in platelet aggregation via interaction with the major platelet integrin $\alpha \operatorname{IIb} \beta 3$ [53], but a physical and functional interaction between cadherin 6 and Tspan 18 on platelets has yet to be explored.

A genome-wide association study on schizophrenia in the Han Chinese population implicated three singlenucleotide polymorphisms in the $5^{\prime}$ untranslated region of Tspan18 [54]. However, this remains controversial, because these polymorphisms were not replicated in all mice was perfused over a collagen-coated flow cell $(30 \mu \mathrm{g} / \mathrm{ml})$ using the Fluxion Bioflux system at a shear rate of $1000 \mathrm{~s}^{-1}$. Coverage of the flow cell by aggregates was measured at 1 min intervals, using thresholding in ImageJ. The upper panel shows quantitated data; a two-way ANOVA with Bonferroni post-test was performed on arcsine-transformed data. Error bars represent the standard error of the mean from three pairs of mice. Lower panels show representative fluorescence images taken at $1 \mathrm{~min}$ intervals. Detailed methods are available online (https://etheses.bham.ac.uk/id/eprint/5903/)

follow-up studies [55-58]. Nevertheless, altered Tspan 18 expression in brain endothelial cell or other brain cell types could affect Orai1/ $\mathrm{Ca}^{2+}$ signaling and impact brain function and neurological disorders such as schizophrenia. For instance, Tspan 18 on endothelial cells could be important for brain function, since endothelial dysfunction in the brain and inflammation is linked to neurological disorders $[59,60]$. Alternatively, Tspan 18 on microglial cells (Fig. 2) could impact on their capacity to mediate synaptic pruning, an excess of which was recently linked to schizophrenia [61]. 
A

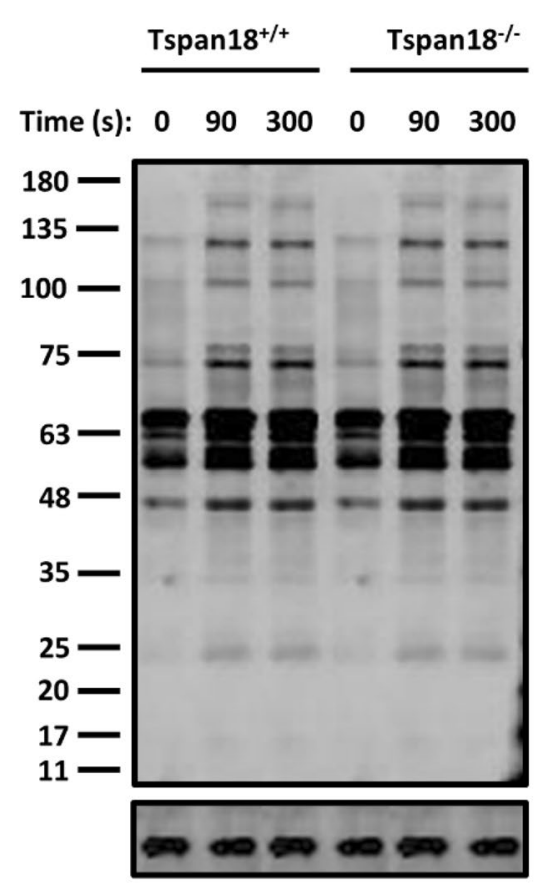

B

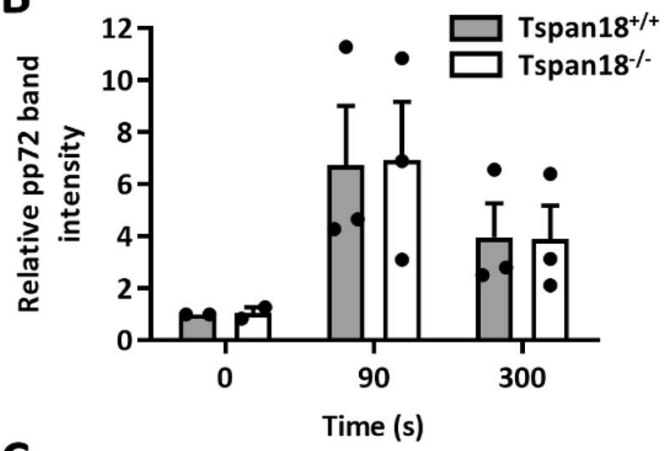

Blot: phosphotyrosine

Blot: tubulin
Fig. 6 GPVI-induced protein tyrosine phosphorylation is normal in Tspan18-deficient platelets. Washed platelets from Tspan $18^{+/+}$and Tspan $18^{-/-}$mice were activated with $3 \mu \mathrm{g} / \mathrm{ml}$ collagen-related peptide (CRP) and samples were taken at 0,90 , and $300 \mathrm{~s}$ time points. a Protein lysates were separated by SDS-PAGE and blotted with a 4G10 anti-phosphotyrosine antibody. The blots were visualized using the Odyssey Infra-Red Imaging System (LI-COR) and band inten-

\section{Résumé and outlook}

In summary, Tspan18 is important in endothelial cells for the cell surface localization of Orai1, $\mathrm{Ca}^{2+}$ signaling, and VWF release. As a result, Tspan 18 deficiency is protective in thrombo-inflammatory models of venous thrombosis and ischemia-reperfusion injury in the heart. $\mathrm{Ca}^{2+}$ signaling and VWF are both critical to endothelial function in haemostasis, inflammation, blood vessel growth, and angiogenesis [5, 38]. Future work should investigate the importance of Tspan 18 in these processes using mouse models of atherosclerosis, ischaemic stroke, and angiogenesis. Generation of Tspan 18 monoclonal antibodies will also be important to determine the expression profile of Tspan 18 at the protein level. Moreover, such antibodies may have inhibitory activity and, thus, therapeutic potential for thrombo-inflammatory diseases such as deep vein thrombosis, retinal neovascularisation, and cancer angiogenesis to deprive a growing tumour of its blood supply. Finally, it will be interesting to investigate the mechanism by which Tspan 18 facilitates Orail trafficking to the

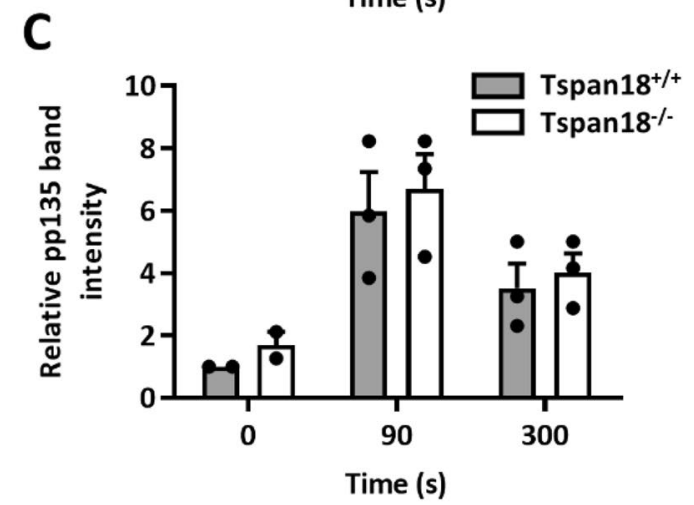

sity of $\mathbf{b}$ the approximately $72 \mathrm{kD}$ band, and $\mathbf{c}$ the approximately 135 $\mathrm{kD}$ band were quantitated. All data were normalized by logarithmic transformation and analysed by two-way ANOVA with Bonferroni post-test. Error bars represent standard error of the mean from three pairs of mice. Detailed methods are available online (https://ethes es.bham.ac.uk/id/eprint/5903/)

endothelial cell surface. Once at the cell surface, it will be important to determine whether and how Tspan 18 regulates Orai1 clustering and/or channel opening. We may then understand why a process as fundamental as storeoperated $\mathrm{Ca}^{2+}$ entry is modified by Tspan 18 in cells such as endothelial cells, but not in others.

Acknowledgements We are grateful to members of the Birmingham Platelet Group for comments on the platelet studies, and to Ana Pombo for her helpful discussions on gene expression and neurological disorders. R.L.G. has been supported by a Ph.D. Studentship from the Biotechnology and Biological Sciences Research Council. C.Z.K. has been supported by a Ph.D. Studentship from the British Heart Foundation (FS/18/9/33388).

\section{Compliance with ethical standards}

Conflict of interest The authors declare they have no conflict of interest.

Ethical approval Mouse platelet experiments were approved by the United Kingdom Home Office according to the Animals (Scientific Procedures) Act 1986. 
Open Access This article is licensed under a Creative Commons Attribution 4.0 International License, which permits use, sharing, adaptation, distribution and reproduction in any medium or format, as long as you give appropriate credit to the original author(s) and the source, provide a link to the Creative Commons licence, and indicate if changes were made. The images or other third party material in this article are included in the article's Creative Commons licence, unless indicated otherwise in a credit line to the material. If material is not included in the article's Creative Commons licence and your intended use is not permitted by statutory regulation or exceeds the permitted use, you will need to obtain permission directly from the copyright holder. To view a copy of this licence, visit http://creativecommons.org/licenses/by/4.0/.

\section{References}

1. Chen J, Chung DW (2018) Inflammation, von Willebrand factor, and ADAMTS13. Blood 132(2):141-147. https://doi. org/10.1182/blood-2018-02-769000

2. Denorme F, Vanhoorelbeke K, De Meyer SF (2019) von Willebrand factor and platelet glycoprotein Ib: a thromboinflammatory axis in stroke. Front Immunol 10:2884. https://doi. org/10.3389/fimmu.2019.02884

3. Stegner D, Klaus V, Nieswandt B (2019) Platelets as modulators of cerebral ischemia/reperfusion injury. Front Immunol 10:2505. https://doi.org/10.3389/fimmu.2019.02505

4. Chimen M, Evryviadou A, Box CL, Harrison MJ, Hazeldine J, Dib LH, Kuravi SJ, Payne H, Price JMJ, Kavanagh D, Iqbal AJ, Lax S, Kalia N, Brill A, Thomas SG, Belli A, Crombie N, Adams RA, Evans SA, Deckmyn H, Lord JM, Harrison P, Watson SP, Nash GB, Rainger GE (2019) Appropriation of GPIbalpha from platelet-derived extracellular vesicles supports monocyte recruitment in systemic inflammation. Haematologica. https://doi.org/10.3324/haematol.2018.215145

5. McCormack JJ, Lopes da Silva M, Ferraro F, Patella F, Cutler DF (2017) Weibel-Palade bodies at a glance. J Cell Sci 130(21):3611-3617. https://doi.org/10.1242/jcs.208033

6. Noy PJ, Gavin RL, Colombo D, Haining EJ, Reyat JS, Payne H, Thielmann I, Lokman AB, Neag G, Yang J, Lloyd T, Harrison N, Heath VL, Gardiner C, Whitworth KM, Robinson J, Koo CZ, Di Maio A, Harrison P, Lee SP, Michelangeli F, Kalia N, Rainger GE, Nieswandt B, Brill A, Watson SP, Tomlinson MG (2019) Tspan18 is a novel regulator of the $\mathrm{Ca}(2+)$ channel Orai1 and von Willebrand factor release in endothelial cells. Haematologica 104(9):1892-1905. https://doi.org/10.3324/haema tol.2018.194241

7. Feske S, Gwack Y, Prakriya M, Srikanth S, Puppel SH, Tanasa B, Hogan PG, Lewis RS, Daly M, Rao A (2006) A mutation in Orai1 causes immune deficiency by abrogating CRAC channel function. Nature 441(7090):179-185. https://doi.org/10.1038/ nature 04702

8. Vig M, Peinelt C, Beck A, Koomoa DL, Rabah D, KoblanHuberson M, Kraft S, Turner H, Fleig A, Penner R, Kinet JP (2006) CRACM1 is a plasma membrane protein essential for store-operated Ca2+ entry. Science 312(5777):1220-1223. https ://doi.org/10.1126/science.1127883

9. Zhang SL, Yeromin AV, Zhang XH, Yu Y, Safrina O, Penna A, Roos J, Stauderman KA, Cahalan MD (2006) Genome-wide RNAi screen of $\mathrm{Ca}(2+)$ influx identifies genes that regulate $\mathrm{Ca}(2+)$ release-activated $\mathrm{Ca}(2+)$ channel activity. Proc Natl Acad Sci USA 103(24):9357-9362. https://doi.org/10.1073/ pnas.0603161103

10. Qiu R, Lewis RS (2019) Structural features of STIM and Orai underlying store-operated calcium entry. Curr Opin Cell Biol 57:90-98. https://doi.org/10.1016/j.ceb.2018.12.012
11. Feske S (2019) CRAC channels and disease-from human CRAC channelopathies and animal models to novel drugs. Cell Calcium 80:112-116. https://doi.org/10.1016/j. ceca.2019.03.004

12. Mammadova-Bach E, Nagy M, Heemskerk JWM, Nieswandt B, Braun A (2019) Store-operated calcium entry in thrombosis and thrombo-inflammation. Cell Calcium 77:39-48. https://doi. org/10.1016/j.ceca.2018.11.005

13. Stauderman KA (2018) CRAC channels as targets for drug discovery and development. Cell Calcium 74:147-159. https://doi. org/10.1016/j.ceca.2018.07.005

14. Termini CM, Gillette JM (2017) Tetraspanins function as regulators of cellular signaling. Front Cell Dev Biol 5:34. https:// doi.org/10.3389/fcell.2017.00034

15. van Deventer SJ, Dunlock VE, van Spriel AB (2017) Molecular interactions shaping the tetraspanin web. Biochem Soc Trans 45(3):741-750. https://doi.org/10.1042/BST20160284

16. Charrin S, Jouannet S, Boucheix C, Rubinstein E (2014) Tetraspanins at a glance. J Cell Sci 127(Pt 17):3641-3648. https://doi. org/10.1242/jcs. 154906

17. Hemler ME (2014) Tetraspanin proteins promote multiple cancer stages. Nat Rev Cancer 14(1):49-60

18. Levy S (2014) Function of the tetraspanin molecule CD81 in B and T cells. Immunol Res 58(2-3):179-185. https://doi. org/10.1007/s12026-014-8490-7

19. Tomlinson MG (2017) Eye-opening potential for tetraspanin Tspan 12 as a therapeutic target for diseases of the retinal vasculature. Circulation 136(2):196-199. https://doi.org/10.1161/CIRCU LATIONAHA.117.028521

20. Matthews AL, Koo CZ, Szyroka J, Harrison N, Kanhere A, Tomlinson MG (2018) Regulation of leukocytes by TspanC8 tetraspanins and the "Molecular Scissor" ADAM10. Front Immunol 9:1451. https://doi.org/10.3389/fimmu.2018.01451

21. Matthews AL, Noy PJ, Reyat JS, Tomlinson MG (2017) Regulation of a disintegrin and metalloproteinase (ADAM) family sheddases ADAM10 and ADAM17: the emerging role of tetraspanins and rhomboids. Platelets 28(4):333-341. https://doi. org/10.1080/09537104.2016.1184751

22. Matthews AL, Szyroka J, Collier R, Noy PJ, Tomlinson MG (2017) Scissor sisters: regulation of ADAM10 by the TspanC 8 tetraspanins. Biochem Soc Trans 45(3):719-730. https://doi. org/10.1042/BST20160290

23. Saint-Pol J, Eschenbrenner E, Dornier E, Boucheix C, Charrin S, Rubinstein E (2017) Regulation of the trafficking and the function of the metalloprotease ADAM10 by tetraspanins. Biochem Soc Trans 45(4):937-944. https://doi.org/10.1042/BST20160296

24. Brummer T, Muller SA, Pan-Montojo F, Yoshida F, Fellgiebel A, Tomita T, Endres K, Lichtenthaler SF (2019) NrCAM is a marker for substrate-selective activation of ADAM10 in Alzheimer's disease. EMBO Mol Med 11(4):e9695. https://doi.org/10.15252/ emmm.201809695

25. Dornier E, Coumailleau F, Ottavi JF, Moretti J, Boucheix C, Mauduit P, Schweisguth F, Rubinstein E (2012) TspanC8 tetraspanins regulate ADAM10/Kuzbanian trafficking and promote Notch activation in flies and mammals. J Cell Biol 199(3):481-496. https:// doi.org/10.1083/jcb.201201133

26. Eschenbrenner E, Jouannet S, Clay D, Chaker J, Boucheix C, Brou C, Tomlinson MG, Charrin S, Rubinstein E (2020) TspanC8 tetraspanins differentially regulate ADAM10 endocytosis and halflife. Life Sci Alliance. https://doi.org/10.26508/lsa.201900444

27. Jouannet S, Saint-Pol J, Fernandez L, Nguyen V, Charrin S, Boucheix C, Brou C, Milhiet PE, Rubinstein E (2016) TspanC8 tetraspanins differentially regulate the cleavage of ADAM10 substrates, Notch activation and ADAM10 membrane compartmentalization. Cell Mol Life Sci 73:1895-1915. https://doi. org/10.1007/s00018-015-2111-z 
28. Koo CZ, Harrison N, Noy PJ, Szyroka J, Matthews AL, Hsia HE, Muller SA, Tushaus J, Goulding J, Willis K, Apicella C, Cragoe B, Davis E, Keles M, Malinova A, McFarlane TA, Morrison PR, Nguyen HTH, Sykes MC, Ahmed H, Di Maio A, Seipold L, Saftig P, Cull E, Pliotas C, Rubinstein E, Poulter NS, Briddon SJ, Holliday ND, Lichtenthaler SF, Tomlinson MG (2020) The tetraspanin Tspan15 is an essential subunit of an ADAM10 scissor complex. J Biol Chem. https://doi.org/10.1074/jbc.RA120.012601

29. Noy PJ, Yang J, Reyat JS, Matthews AL, Charlton AE, Furmston J, Rogers DA, Rainger GE, Tomlinson MG (2016) TspanC8 tetraspanins and a disintegrin and metalloprotease 10 (ADAM10) interact via their extracellular regions: evidence for distinct binding mechanisms for different TspanC8 proteins. J Biol Chem 291(7):3145-3157. https://doi.org/10.1074/jbc.M115.703058

30. Reyat JS, Chimen M, Noy PJ, Szyroka J, Rainger GE, Tomlinson MG (2017) ADAM10-interacting tetraspanins Tspan5 and Tspan 17 regulate VE-cadherin expression and promote $\mathrm{T}$ lymphocyte transmigration. J Immunol 199(2):666-676. https://doi. org/10.4049/jimmunol.1600713

31. Saint-Pol J, Billard M, Dornier E, Eschenbrenner E, Danglot L, Boucheix C, Charrin S, Rubinstein E (2017) New insights into the tetraspanin Tspan5 using novel monoclonal antibodies. J Biol Chem 292(23):9551-9566. https://doi.org/10.1074/jbc. M116.765669

32. Seipold L, Altmeppen H, Koudelka T, Tholey A, Kasparek P, Sedlacek R, Schweizer M, Bar J, Mikhaylova M, Glatzel M, Saftig $P$ (2018) In vivo regulation of the A disintegrin and metalloproteinase 10 (ADAM10) by the tetraspanin 15. Cell Mol Life Sci 75:3251-3267. https://doi.org/10.1007/s00018-018-2791-2

33. Zimmerman B, Kelly B, McMillan BJ, Seegar TC, Dror RO, Kruse AC, Blacklow SC (2016) Crystal structure of a full-length human tetraspanin reveals a cholesterol-binding pocket. Cell 167(4):1041-1051. https://doi.org/10.1016/j.cell.2016.09.056

34. Tabula Muris C (2018) Overall c, Logistical c, Organ c, processing, Library p, sequencing, Computational data a, Cell type a, Writing g, Supplemental text writing g, Principal i. Single-cell transcriptomics of 20 mouse organs creates a Tabula Muris. Nature 562(7727):367-372. https://doi.org/10.1038/s4158 6-018-0590-4

35. Kanaji S, Fahs SA, Shi Q, Haberichter SL, Montgomery RR (2012) Contribution of platelet vs. endothelial VWF to platelet adhesion and hemostasis. J Thromb Haemost 10(8):1646-1652. https://doi.org/10.1111/j.1538-7836.2012.04797.x

36. Verhenne S, Denorme F, Libbrecht S, Vandenbulcke A, Pareyn I, Deckmyn H, Lambrecht A, Nieswandt B, Kleinschnitz C, Vanhoorelbeke K, De Meyer SF (2015) Platelet-derived VWF is not essential for normal thrombosis and hemostasis but fosters ischemic stroke injury in mice. Blood 126(14):1715-1722. https ://doi.org/10.1182/blood-2015-03-632901

37. Marass M, Beisaw A, Gerri C, Luzzani F, Fukuda N, Gunther S, Kuenne C, Reischauer S, Stainier DYR (2019) Genome-wide strategies reveal target genes of Npas4l associated with vascular development in zebrafish. Development. https://doi.org/10.1242/ dev. 173427

38. Randi AM, Smith KE, Castaman G (2018) von Willebrand factor regulation of blood vessel formation. Blood 132(2):132-140. https ://doi.org/10.1182/blood-2018-01-769018

39. Yen M, Lewis RS (2019) Numbers count: how STIM and Orai stoichiometry affect store-operated calcium entry. Cell Calcium 79:35-43. https://doi.org/10.1016/j.ceca.2019.02.002

40. Zhou Y, Cai X, Nwokonko RM, Loktionova NA, Wang Y, Gill DL (2017) The STIM-Orai coupling interface and gating of the Orai1 channel. Cell Calcium 63:8-13. https://doi.org/10.1016/j. ceca.2017.01.001

41. Stilgenbauer S, Aurran Schleinitz T, Eichhorst B, Lang F, Offner F, Rossi JF, Schroyens W, Van Den Neste E, Ysebaert L, von
Wangenheim U, Ursula Kress U, Blum P, Zenz T (2019) Phase 1 first-in-human trial of the anti-CD37 antibody BI 836826 in relapsed/refractory chronic lymphocytic leukemia. Leukemia. https://doi.org/10.1038/s41375-019-0475-z

42. Lewandrowski U, Wortelkamp S, Lohrig K, Zahedi RP, Wolters DA, Walter U, Sickmann A (2009) Platelet membrane proteomics: a novel repository for functional research. Blood 114(1):e10-19

43. Tomlinson MG (2009) Platelet tetraspanins: small but interesting. J Thromb Haemost 7(12):2070-2073. https://doi.org/10.111 1/j.1538-7836.2009.03613.x

44. Macaulay IC, Tijssen MR, Thijssen-Timmer DC, Gusnanto A, Steward M, Burns P, Langford CF, Ellis PD, Dudbridge F, Zwaginga JJ, Watkins NA, van der Schoot CE, Ouwehand WH (2007) Comparative gene expression profiling of in vitro differentiated megakaryocytes and erythroblasts identifies novel activatory and inhibitory platelet membrane proteins. Blood 109(8):3260-3269

45. Protty MB, Watkins NA, Colombo D, Thomas SG, Heath VL, Herbert JM, Bicknell R, Senis YA, Ashman LK, Berditchevski F, Ouwehand WH, Watson SP, Tomlinson MG (2009) Identification of Tspan9 as a novel platelet tetraspanin and the collagen receptor GPVI as a component of tetraspanin microdomains. Biochem J 417(1):391-400

46. Rowley JW, Oler AJ, Tolley ND, Hunter BN, Low EN, Nix DA, Yost CC, Zimmerman GA, Weyrich AS (2011) Genome-wide RNA-seq analysis of human and mouse platelet transcriptomes. Blood 118(14):e101-111. https://doi.org/10.1182/blood-2011-03339705

47. Inoue O, Suzuki-Inoue K, Dean WL, Frampton J, Watson SP (2003) Integrin alpha2beta1 mediates outside-in regulation of platelet spreading on collagen through activation of Src kinases and PLCgamma2. J Cell Biol 160(5):769-780

48. Mazzucato M, Cozzi MR, Battiston M, Jandrot-Perrus M, Mongiat M, Marchese P, Kunicki TJ, Ruggeri ZM, De Marco L (2009) Distinct spatio-temporal $\mathrm{Ca} 2+$ signaling elicited by integrin alpha2beta1 and glycoprotein VI under flow. Blood 114(13):27932801. https://doi.org/10.1182/blood-2008-12-193490

49. Braun A, Varga-Szabo D, Kleinschnitz C, Pleines I, Bender M, Austinat M, Bosl M, Stoll G, Nieswandt B (2009) Orai1 (CRACM1) is the platelet SOC channel and essential for pathological thrombus formation. Blood 113(9):2056-2063. https://doi. org/10.1182/blood-2008-07-171611

50. Fairchild CL, Conway JP, Schiffmacher AT, Taneyhill LA, Gammill LS (2014) FoxD3 regulates cranial neural crest EMT via downregulation of tetraspanin 18 independent of its functions during neural crest formation. Mech Dev 132:1-12. https://doi. org/10.1016/j.mod.2014.02.004

51. Fairchild CL, Gammill LS (2013) Tetraspanin 18 is a FoxD3responsive antagonist of cranial neural crest epithelial-to-mesenchymal transition that maintains cadherin-6B protein. J Cell Sci 126(Pt 6):1464-1476. https://doi.org/10.1242/jcs.120915

52. Casal JI, Bartolome RA (2019) Beyond N-cadherin, relevance of cadherins 5, 6 and 17 in cancer progression and metastasis. Int $\mathrm{J}$ Mol Sci. https://doi.org/10.3390/ijms20133373

53. Dunne E, Spring CM, Reheman A, Jin W, Berndt MC, Newman DK, Newman PJ, Ni H, Kenny D (2012) Cadherin 6 has a functional role in platelet aggregation and thrombus formation. Arterioscler Thromb Vasc Biol 32(7):1724-1731. https://doi. org/10.1161/ATVBAHA.112.250464

54. Yue WH, Wang HF, Sun LD, Tang FL, Liu ZH, Zhang HX, Li WQ, Zhang YL, Zhang Y, Ma CC, Du B, Wang LF, Ren YQ, Yang YF, Hu XF, Wang Y, Deng W, Tan LW, Tan YL, Chen Q, Xu GM, Yang GG, Zuo XB, Yan H, Ruan YY, Lu TL, Han X, Ma XH, Wang Y, Cai LW, Jin C, Zhang HY, Yan J, Mi WF, Yin XY, Ma WB, Liu Q, Kang L, Sun W, Pan CY, Shuang M, Yang FD, Wang CY, Yang JL, Li KQ, Ma X, Li LJ, Yu X, Li QZ, Huang X, Lv LX, Li T, Zhao GP, Huang W, Zhang XJ, Zhang D 
(2011) Genome-wide association study identifies a susceptibility locus for schizophrenia in Han Chinese at 11p11.2. Nat Genet 43(12):1228-1231. https://doi.org/10.1038/ng.979

55. Li Z, Shen T, Xin R, Liang B, Jiang J, Ling W, Wei B, Su L (2017) Association of NKAPL, TSPAN18, and MPC2 gene variants with schizophrenia based on new data and a meta-analysis in Han Chinese. Acta Neuropsychiatr 29(2):87-94. https://doi.org/10.1017/ neu. 2016.36

56. Wu L, Chen F, Wei J, Shen Y, Xu Q (2016) Study of the tetraspanin 18 association with schizophrenia in a Han Chinese population. Psychiatry Res 241:263-266. https://doi.org/10.1016/j.psych res.2016.03.057

57. Yuan J, Jin C, Qin HD, Wang J, Sha W, Wang M, Zhang Y, Zhang F, Li J, Li J, Yu S, Qi S, Shugart YY (2013) Replication study confirms link between TSPAN18 mutation and schizophrenia in Han Chinese. PLoS ONE 8(3):e58785. https://doi.org/10.1371/ journal.pone.0058785

58. Zhang B, Li DX, Lu N, Fan QR, Li WH, Feng ZF (2015) Lack of association between the TSPAN18 gene and schizophrenia based on new data from Han Chinese and a meta-analysis. Int J Mol Sci 16(6):11864-11872. https://doi.org/10.3390/ijms160611864

59. Bauer ME, Teixeira AL (2019) Inflammation in psychiatric disorders: what comes first? Ann NY Acad Sci 1437(1):57-67. https:// doi.org/10.1111/nyas.13712

60. Najjar S, Pahlajani S, De Sanctis V, Stern JNH, Najjar A, Chong D (2017) Neurovascular unit dysfunction and blood-brain barrier hyperpermeability contribute to schizophrenia neurobiology: a theoretical integration of clinical and experimental evidence. Front Psychiatry 8:83. https://doi.org/10.3389/fpsyt.2017.00083

61. Sellgren CM, Gracias J, Watmuff B, Biag JD, Thanos JM, Whittredge PB, Fu T, Worringer K, Brown HE, Wang J, Kaykas A, Karmacharya R, Goold CP, Sheridan SD, Perlis RH (2019) Increased synapse elimination by microglia in schizophrenia patient-derived models of synaptic pruning. Nat Neurosci 22(3):374-385. https://doi.org/10.1038/s41593-018-0334-7

62. Kelley LA, Mezulis S, Yates CM, Wass MN, Sternberg MJ (2015) The Phyre2 web portal for protein modeling, prediction and analysis. Nat Protoc 10(6):845-858. https://doi.org/10.1038/nprot .2015 .053

63. Hou X, Burstein SR, Long SB (2018) Structures reveal opening of the store-operated calcium channel Orai. Elife. https://doi. org/10.7554/eLife.36758

64. Hou X, Pedi L, Diver MM, Long SB (2012) Crystal structure of the calcium release-activated calcium channel Orai. Science 338(6112):1308-1313. https://doi.org/10.1126/science.1228757

Publisher's Note Springer Nature remains neutral with regard to jurisdictional claims in published maps and institutional affiliations. 